\title{
Small interfering RNA-mediated knockdown of Twist attenuates the aggressive phenotypes of human endometrial carcinoma Ishikawa cells
}

\author{
YILIAN PAN, XIAOYI LIU and YONG HUANG \\ Department of Obstetrics and Gynecology, The International Peace Maternity \\ and Child Health Hospital, Shanghai 200030, P.R. China
}

Received March 8, 2016; Accepted March 3, 2017

DOI: $10.3892 /$ etm.2017.5214

\begin{abstract}
The present study aimed to determine the effect of Twist downregulation on the proliferation, apoptosis and migration of human endometrial carcinoma Ishikawa cells. Endogenous expression of the Twist transcription factor was knocked down by delivery of Twist-targeting small interfering RNA (siRNA). Changes in the expression of epithelial-mesenchymal transition biomarkers, namely epithelial (E)-cadherin, neural (N)-cadherin and Twist, were determined by western blot analysis. Cell cycle distribution and apoptosis were evaluated by flow cytometry. Cell proliferation and migration were analyzed using cell-counting and wound-healing assays, respectively. Transfection with Twist siRNA led to a significant reduction in the expression of Twist and $\mathrm{N}$-cadherin $(\mathrm{P}<0.05)$, while significantly increasing the expression of E-cadherin, relative to negative control transfectants (all $\mathrm{P}<0.05)$. Proliferation was also significantly decreased in Ishikawa cells transfected with Twist siRNA $(\mathrm{P}<0.05)$, which was accompanied by an increased rate of apoptosis and cell cycle arrest at S-phase. In addition, Twist downregulation led to a significant reduction in cell migration $(\mathrm{P}<0.05)$. These data suggest that Twist serves a role in the regulation of cell proliferation and migration in Ishikawa cells and may represent a potential target for the treatment of human endometrial carcinoma.
\end{abstract}

\section{Introduction}

Endometrial carcinoma is one of the most prevalent gynecological malignancies (1). Despite advances in therapeutic approaches, many patients with endometrial carcinoma

Correspondence to: Dr Yong Huang, Department of Obstetrics and Gynecology, The International Peace Maternity and Child Health Hospital, 910 Hengshan Road, Xu, Shanghai 200030, P.R. China E-mail: yonghuang2016@qq.com

Key words: apoptosis, cell cycle arrest, endometrial carcinoma, migration, Twist develop localized, recurrent and/or distant metastases (2). Therefore, it is important to identify the key regulators of endometrial carcinoma progression and metastasis to develop more effective therapies to treat endometrial carcinoma.

Epithelial-mesenchymal transition (EMT) is a crucial event in tumor invasion and metastasis, whereby epithelial cells lose their polarity and cell-cell contacts and undergo cytoskeletal remodeling (3). EMT is typically associated with a downregulation of epithelial (E)-cadherin and upregulation of neural (N)-cadherin (4), and decreases in E-cadherin expression are associated with a more infiltrative growth pattern in a variety of cancers, including non-small-cell lung cancer, prostate cancer and endometrial cancer (5-7). The transcription factor Twist has been identified as an inducer of EMT by its transcriptional repression of E-cadherin $(8,9)$. Twist is also involved in tumor cell proliferation and survival (10) and it has been documented that Twist mediates aggressive phenotypes in human colorectal cancer cells, thus contributing to cell migration, invasion and chemoresistance (11). Twist also facilitates EMT and cell motility in breast cancer through the integrin $\beta 1$ subunit-focal adhesion kinase/integrin-linked kinase signaling axis (12). Furthermore, during cervical carcinogenesis, Twist has been implicated in the induction of EMT by regulating the tumor growth factor- $\beta / \operatorname{Smad} 3$ signaling pathway (13). Therefore, Twist may be a promising target of anticancer therapies.

However, the biological functions of Twist in human endometrial carcinoma remain unknown. Through loss-of-function experiments, the present study aimed to elucidate the roles of Twist in the proliferation, migration, invasion and EMT of endometrial carcinoma cells.

\section{Materials and methods}

Cell culture. Human endometrial carcinoma Ishikawa cells were provided by Professor XiaoPing Wan (Department of Gynecology, Shanghai First People's Hospital, Shanghai, China). Cells were cultured in RPMI-1640 medium (Invitrogen; Thermo Fisher Scientific, Inc., Waltham, MA, USA) with $10 \%$ fetal bovine serum (Invitrogen; Thermo Fisher Scientific, Inc.), $100 \mathrm{U} / \mathrm{ml}$ penicillin and $100 \mu \mathrm{g} / \mathrm{ml}$ streptomycin in a humidified incubator at $37^{\circ} \mathrm{C}$ and $5 \% \mathrm{CO}_{2}$ for $48 \mathrm{~h}$. 
Transfection with Twist small interfering RNA (siRNA). Three siRNAs targeting different sites in the mRNA of Twist and one non-targeting control siRNA were designed and synthesized by Shanghai Minghong Biotechnologies Co., Ltd. (Shanghai, China). The sequences of the Twist siRNAs were as follows: 5'-AAGCUGAGCAAGAUUCAGACC-3', 5'-AGCGGGUCA UGGCUAACGUGC-3' and 5'-AGGUACAUCGACUUCCUG UAC-3'. The Twist siRNAs (50 nM of each) were transfected into Ishikawa cells, individually and in combination to evaluated transfection efficiency compared with the control and non-targeting control siRNA group, using Lipofectamine ${ }^{\circledR}$ 2000 (Invitrogen; Thermo Fisher Scientific, Inc.), according to the manufacturer's protocol. The mixture of three Twist siRNAs $(1: 1: 1 ; 50 \mathrm{nM})$ was used to determine the biological function of Twist. siRNA transfection efficiency was determined by an in-parallel transfection with BLOCK-iT Alexa Fluor red fluorescent oligonucleotide (Invitrogen; Thermo Fisher Scientific, Inc.). The fluorescent signal was then observed under a fluorescent microscope (Leica DFC550 Microsystems GmbH, Wetzlar, Germany; magnification, $\mathrm{x} 400$ ). When transfection efficiency was $>85 \%$, transfected cells were used in the following experiments.

Western blot analysis. Following transfection, cells were lysed in ice-cold lysis buffer (50 mmol/1 Tris-HCl, $\mathrm{pH} 7.4$, $150 \mathrm{mmol} / 1 \mathrm{NaCl}, 1 \% \mathrm{NP}-40$ and $0.5 \%$ sodium deoxycholate) supplemented with protease inhibitors (Roche Diagnostics, Indianapolis, IN, USA) for $30 \mathrm{~min}$ at $4^{\circ} \mathrm{C}$. The supernatant of cell lysates was obtained by centrifugation for $10 \mathrm{~min}$ at $12,000 \mathrm{xg}$ at $4^{\circ} \mathrm{C}$. A BCA Protein Assay kit (Beyotime Institute of Biotechnology, Haimen, China) was used to determine protein concentrations. Equal amounts of protein $(20 \mu \mathrm{g}$ per lane) were separated by 8 or $12 \%$ SDS-PAGE and transferred onto polyvinylidene difluoride membranes.

Following blocking with 5\% skimmed milk for $2 \mathrm{~h}$ at room temperature, membranes were probed with anti-Twist (cat. no. 46702), anti-E-cadherin (cat. no. 14472), anti-N-cadherin (cat. no. 14215) or anti-glyceraldehyde 3-phosphate dehydrogenase (GAPDH) (cat. no. 2118; all 1:1,000; all Cell Signaling Technology, Inc., Danvers, MA, USA) antibodies overnight at $4{ }^{\circ} \mathrm{C}$, followed by incubation with horseradish peroxidase-conjugated secondary antibody (1:5,000; cat. nos. 7074 and 7076; Cell Signaling Technology, Inc.) for $1 \mathrm{~h}$ at room temperature. Blots were developed using an enhanced chemiluminescence kit (GE Healthcare Life Sciences, Chalfont, UK). The intensities of immunoreactive bands were measured by computerized image analysis using Quantity One v4.62 software (Bio-Rad Laboratories, Inc., Hercules, CA, USA) and normalized to GAPDH expression. A total of 3 replicates were performed.

Cell counting kit (CCK8) assay. Ishikawa cells $\left(1.0 \times 10^{4}\right.$ cells/well) were plated in 96 -well plates (three wells per group) with RPMI-1640 medium with $10 \%$ fetal bovine serum, $100 \mathrm{U} / \mathrm{ml}$ penicillin and $100 \mu \mathrm{g} / \mathrm{ml}$ streptomycin in a humidified incubator at $37^{\circ} \mathrm{C}$ and $5 \% \mathrm{CO}_{2}$ and treated with honokiol $(0.01 \mathrm{mg} / \mathrm{ml})$ for $0-4$ days. On days $0-4$ after seeding, CCK-8 solution (Dojindo Molecular Technologies, Inc., Kumamoto, Japan) was administered to cells, according to the manufacturer's instructions, and cell proliferation was measured at $490 \mathrm{~nm}$ using an ELISA reader SpectraMax 190 microplate reader (Bio-Rad Laboratories, Inc.).

Quantification of apoptosis by flow cytometry. Cell apoptosis was analyzed using an Annexin-V/propidium iodide (PI) assay. Briefly, cells were digested with $0.25 \%$ trypsin (Invitrogen; Thermo Fisher Scientific, Inc.), washed and resuspended in binding buffer. Annexin V-FITC and PI were then added (BD Pharmingen; BD Biosciences, Franklin Lakes, NJ, USA) and apoptotic cells were detected using a flow cytometer (Beckman Coulter, Inc., Brea, CA, USA) washed and suspended in staining buffer containing $1 \mu \mathrm{g} / \mathrm{ml}$ PI and $0.025 \mu \mathrm{g} / \mathrm{ml}$ Annexin V-fluorescein isothiocyanate. Double labeling was performed at room temperature for $10 \mathrm{~min}$ in the dark. Following incubation, the percentage of apoptotic cells was measured by flow cytometry FC500 (Beckman Coulter, Inc., CA, USA). The software used for analysis is Cytometer supplied by the instrument company.

Cell cycle analysis. Ishikawa cells $\left(1 \times 10^{6}\right.$ cells/well) were plated with RPMI-1640 medium in 6-well plates (three wells per group) and treated with vehicle or honokiol (5 or $10 \mu \mathrm{M})$ for $48 \mathrm{~h}$. For cell cycle assay, cells were washed twice with ice cold PBS, fixed in $70 \%$ ethanol at $-20^{\circ} \mathrm{C}$ for $4 \mathrm{~h}$ and incubated with $50 \mathrm{mg} / \mathrm{ml}$ PI (Sigma-Aldrich; Merck KGaA). After fixation, cells were washed by phosphate buffer 2 times and then stained by $50 \mathrm{ug} / \mathrm{ml}$ PI in $500 \mathrm{ul}$ PBS containing $100 \mathrm{ug} / \mathrm{ml}$ RNase A for $30 \mathrm{~min}$. Cell cycle distribution was assessed by flow cytometry FC500 (Beckman Coulter, Inc., CA, USA) and analyzed by the software provided.

Wound healing assay. Ishikawa cells ( $1 \times 10^{6}$ cells/well) were plated in 6-well plates and grown to $70-80 \%$ confluence with RMPI-1640 without fetal bovine serum for $24 \mathrm{~h}$. Using a 200- $\mu$ 1 pipette tip, a scratch wound was made through the cell monolayer. Cells were washed with PBS to remove any detached cells and incubated in RMPI-1640 with $10 \%$ fetal bovine serum at $37^{\circ} \mathrm{C}$ for $48 \mathrm{~h}$. The distance between the two sides of the wound was measured with a light microscope before and after wound healing.

Statistical analysis. Data were expressed as the mean \pm standard deviation and analyzed by one-way analysis of variance followed by a Tukey's multiple comparisons test. Statistical differences were determined using SPSS 13.0 software (SPSS, Inc., Chicago, IL, USA) and $\mathrm{P}<0.05$ was considered to indicate a statistically significant difference. All experiments have been replicated three times.

\section{Results}

siRNA knockdown of endogenous Twist in Ishikawa cells. To downregulate the expression of Twist in human endometrial carcinoma Ishikawa cells, three different Twist siRNAs were individually transfected into cells. Ishikawa cells without siRNA transfection were used as control group and cells with non-targeting control siRNA transfection were used as mock group to eliminate the effect of transfection treatment. As presented in Fig. 1, transfection with each of the Twist siRNAs lead to a marked reduction in the levels of Twist protein levels 


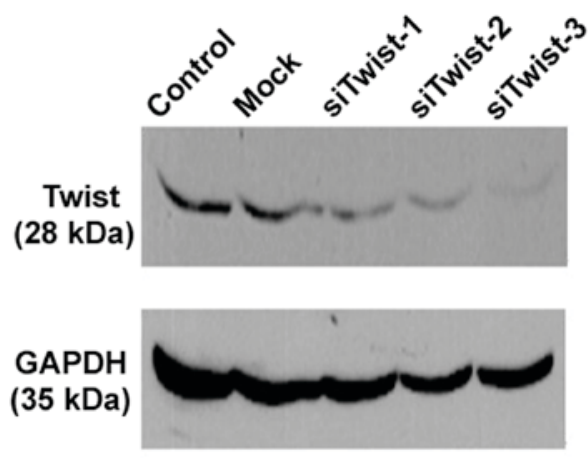

Figure 1. Expression of Twist protein following siRNA knockdown in human endometrial carcinoma Ishikawa cells. Western blot analysis was performed to measure the levels of Twist protein in non-transfected, non-targeting siRNA-transfected and Twist siRNA-transfected Ishikawa cells. Representative blots from three independent experiments are presented. Control, non-transfected cells; mock, non-targeting siRNA-transfected cells; siTwist, Twist siRNA; siRNA, small interfering RNA.

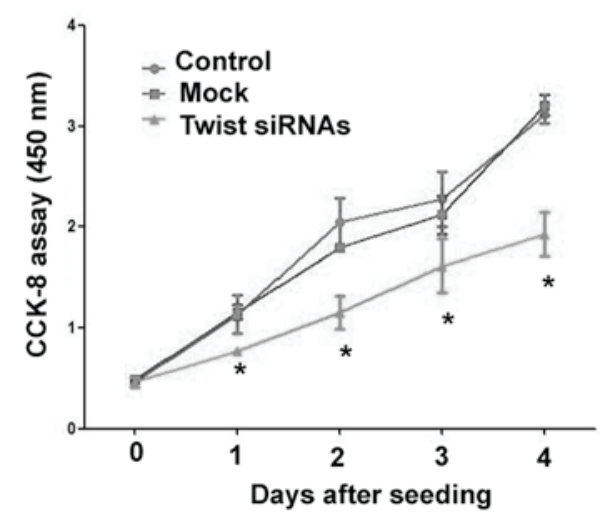

Figure 2. Downregulation of Twist inhibits Ishikawa cell proliferation. Non-transfected, non-targeting siRNA-transfected and Twist siRNA-transfected Ishikawa cells were cultured for 4 days and cell proliferation was measured daily using a CCK-8 assay. The plot represents the mean results of three independent experiments. Twist siRNA-transfected Ishikawa cells were transfected with a mixture of all three Twist siRNA. ${ }^{*} \mathrm{P}<0.05$ vs. control cells. CCK-8, Cell Counting Kit-8; control, non-transfected cells; mock, non-targeting siRNA-transfected cells; control, non-transfected cells; Mock, non-targeting siRNA-transfected cells; siRNA, small interfering RNA.

by $48 \mathrm{~h}$ post-transfection, relative to mock and control cells. As expected, expression of GAPDH was unaltered by Twist siRNA transfection. These results indicate that the RNA interference assay was specific and effective. Therefore, Ishikawa cells were transfected with a mixture of all three Twist siRNAs in subsequent experiments to determine the biological functions of Twist.

Downregulation of Twist inhibits Ishikawa cell proliferation. Results from the CCK-8 assay demonstrated that downregulation of Twist led to a significant reduction in the proliferation of Ishikawa cells, relative to mock cells transfected with non-targeting siRNA $(\mathrm{P}<0.05$; Fig. 2). Flow cytometric analysis also indicated that knockdown of Twist significantly induced apoptosis ( 4-fold) in Ishikawa cells compared with control and mock-transfected cells $(\mathrm{P}<0.05$; Fig. $3 \mathrm{~A}$ and $\mathrm{B})$. In addition, Twist downregulation led to a marked decrease in the percentage of G0/G1 phase-cells and a concomitant
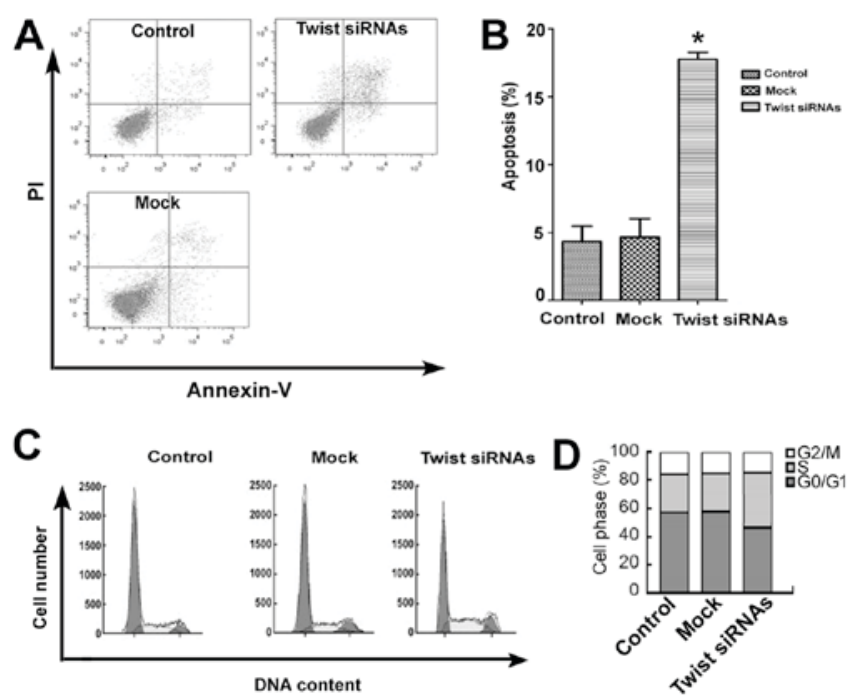

Figure 3. Effects of Twist downregulation on the apoptosis and cell cycle distribution of Ishikawa cells. (A) Detection of apoptosis in non-transfected, non-targeting siRNA-transfected and Twist siRNA-transfected Ishikawa cells following Annexin-V/PI staining. Cells in the first and fourth quadrants represent the apoptotic cells (Annexin V+). (B) Percentages of apoptotic cells determined by flow cytometry analysis. (C) Flow cytometric analysis of cell cycle distribution in control, mock-transfected and Twist siRNA-transfected Ishikawa cells. The major peak represents the G1 stage Ishikawa cells. (D) Percentages of cell cycle distributions. Bar graphs represent the results of three independent experiments. Twist siRNA-transfected Ishikawa cells were transfected with a mixture of all three Twist siRNA. $\mathrm{P}<0.05$ vs. control cells. Control, non-transfected cells; mock, non-targeting siRNA-transfected cells; PI, propidium iodide; siRNA, small interfering RNA.

increase in the percentage of S-phase cells, indicating an arrest of the cell cycle predominantly in the S-phase following Twist knockdown (Fig. 3C and D).

Twist downregulation impairs Ishikawa cell migration. The effects of Twist knockdown on the migration of Ishikawa cells were subsequently evaluated. In a wound-healing assay, it was observed that knockdown of Twist significantly attenuated the migration of Ishikawa cells, compared with control cells (P<0.05; Fig. 4).

Twist downregulation affects the expression of EMT-related proteins. The effects of Twist downregulation on the expression of EMT-related proteins were also evaluated. As depicted in Fig. 5, it was observed that Twist silencing significantly induced the expression of E-cadherin and significantly decreased the expression of $\mathrm{N}$-cadherin, relative to control cells (both $\mathrm{P}<0.05$ ).

\section{Discussion}

Previous results have indicated that Twist expression is correlated with the invasiveness of tumor cells and a poor prognosis in many solid cancers, including prostate cancer and hepatocellular carcinoma $(8,14,15)$. In addition, Twist has the ability to trigger EMT in a variety of tumor cells, including prostate cancer and breast cancer (16). However, no previous results have identified a role of Twist in the invasion and metastasis of endometrial carcinoma. In the present study, it was determined that knockdown of Twist led to a significant upregulation in 

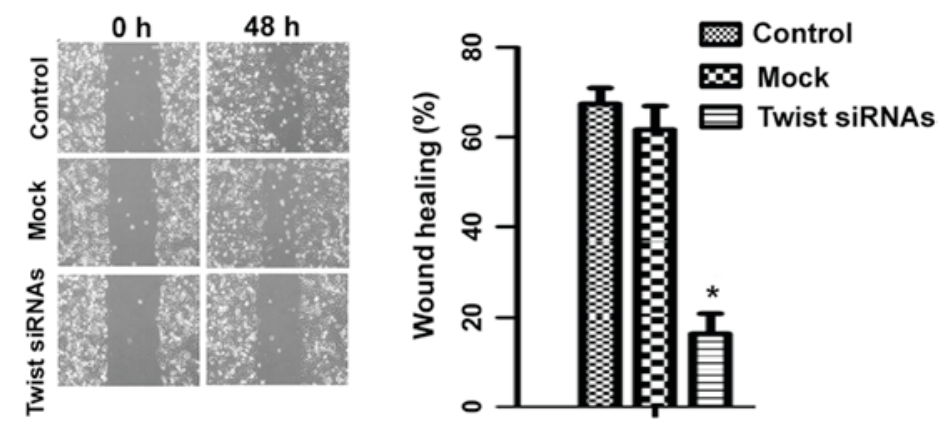

Figure 4. Twist silencing inhibits the migration of Ishikawa cells. A wound-healing assay was conducted to evaluate the migratory capacity of non-transfected, non-targeting siRNA-transfected and Twist siRNA-transfected Ishikawa cells. Representative images were obtained prior to and $48 \mathrm{~h}$ following wounding. The bar graph represents the results of three independent experiments. Twist siRNA-transfected Ishikawa cells were transfected with a mixture of all three Twist siRNA. "P<0.05 vs. control cells. Control, non-transfected cells; mock, non-targeting siRNA-transfected cells; siRNA, small interfering RNA.
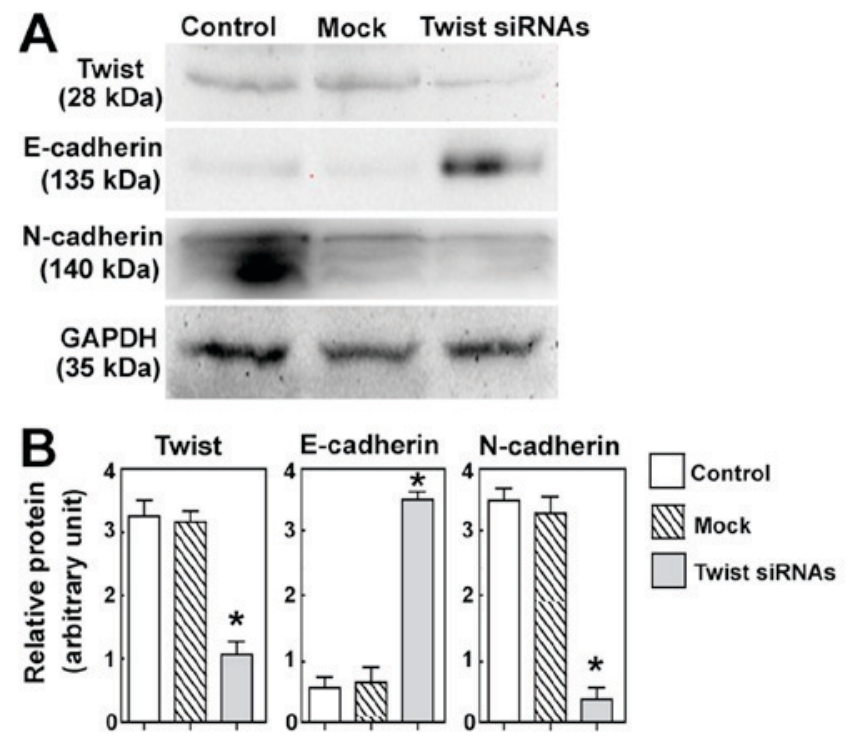

Figure 5. Twist silencing affects the expression of EMT-related proteins. Western blot analysis was performed to measure the levels of EMT-related proteins (E-cadherin and $\mathrm{N}$-cadherin) in non-transfected, non-targeting siRNA-transfected and Twist siRNA-transfected Ishikawa cells. (A) Representative blots from three independent experiments are shown. (B) Relative protein levels normalized to GAPDH expression. Twist siRNA-transfected Ishikawa cells were transfected with a mixture of all three Twist siRNA. "P<0.05 vs. control cells. EMT, epithelial-mesenchyma transition; E-cadherin, epithelial cadherin; N-cadherin, neural cadherin control, non-transfected cells; mock, non-targeting siRNA-transfected cells; siRNA, small interfering RNA.

E-cadherin and a significant downregulation in N-cadherin. A wound scratch assay also demonstrated that the migratory rate of Twist-knockdown cells was significantly lower than that of control cells. These results suggest that the decreases in cell migration mediated by Twist silencing were associated with a reversion to an epithelial cell phenotype, resulting in an impaired migratory capacity in endometrial carcinoma cells.

Loss of E-cadherin expression is a critical component of EMT. A primary mechanism by which E-cadherin expression is inhibited is through the upregulation of its transcriptional repressors. Yang et al (8) documented that overexpression of Twist in human mammary epithelial cells inhibited the promoter activity of E-cadherin. In addition, Twist overexpression in mammary and prostate cancer cells leads to a decrease in E-cadherin expression, thus promoting EMT and cell migration $(8,14)$. Consistent with these results, the current study identified a statistically significant inverse association between Twist and E-cadherin expression in endometrial carcinoma cells. Yang et al (8) also demonstrated that Twist may act as an EMT inducer, resulting in enhanced tumor invasion and metastasis in a model of breast cancer. Collectively, these results suggest that the delivery of Twist siRNA may be a potential therapeutic approach for the treatment of endometrial carcinoma.

Cell cycle control is the major regulatory mechanism of cell growth. In particular, activation of the tumor suppressor protein p53 serves a role in the regulation of cell cycle arrest and apoptosis (17). Many chemotherapeutic drugs and Chinese herbal medicines arrest the cell cycle and subsequently induce cell death $(18,19)$. It has also been suggested that Twist has oncogenic properties. For instance, it was demonstrated that overexpression of Twist in rhabdomyosarcoma inhibits myc-induced apoptosis and interfere with the tumor suppressive-effects of p53 (20). Furthermore, upregulation of Twist has been associated with malignant transformation in T-cell lymphoma (21) and forced expression of Twist may trigger resistance in human cancer cells against drugs that inhibit microtubule formation, including taxol and vincristine (14). Vichalkovski et al (22) demonstrated that phosphorylation of the transcription factor Twist-1 by protein kinase B at Ser42 inhibits the activity of p53 in response to DNA damage. Indeed, it has been demonstrated that Twist participates in development and progression of nasopharyngeal carcinoma and breast cancers $(23,24)$. Therefore, the present study investigated the regulatory effect of Twist on endometrial carcinoma cells by delivering Twist siRNAs into Ishikawa cells. The growth of cells transfected with Twist siRNA was significantly decreased and subsequent assays indicated that the suppressive effects of Twist on cell proliferation occurred, at least in part, through disruption of the S/M transition.

In conclusion, the present results indicate that Twist affects the proliferation, migration and cell cycle distribution of endometrial carcinoma cells, all of which may be associated with its regulatory effects on EMT. These findings suggest that Twist is a potential target for the treatment of endometrial carcinoma. Further in vivo studies are now warranted to confirm the roles of Twist in endometrial carcinoma. 


\section{Acknowledgements}

The present study was supported by the Shanghai Medical Science Development Foundation of China (grant no. 3030503).

\section{References}

1. Jemal A, Thomas A, Murray T and Thun M: Cancer statistics, 2002. CA Cancer J Clin 52: 23-47, 2002.

2. Lotocki RJ, Copeland LJ, DePetrillo AD and Muirhead W: Stage I endometrial adenocarcinoma:Treatment results in 835 patients. Am J Obstet Gynecol 146: 141-144, 1983.

3. Tsai JH, and Yang J: Epithelial-mesenchymal plasticity in carcinoma metastasis. Genes Dev 27: 2192-2206, 2013.

4. Wijnhoven BP, Dinjens WN and Pignatelli M: E-cadherin-catenin cell-cell adhesion complex and human cancer. Br J Surg 87: 992-1005, 2000

5. Bremnes RM, Veve R, Gabrielson E, Hirsch FR, Baron A Bemis L, Gemmill RM, Drabkin HA and Franklin WA: High-throughput tissue microarray analysis used to evaluate biology and prognostic significance of the E-cadherin pathway in non-small-cell lung cancer. J Clin Oncol 20: 2417-2428, 2000

6. Cheng L, Nagabhushan M, Pretlow TP, Pretlow TP, Amini SB and Pretlow TG: Expression of E-cadherin in primary and metastatic prostate cancer. Am J Pathol 148: 1375-1380, 1996

7. Sakuragi N1, Nishiya M, Ikeda K, Ohkouch T, Furth EE, Hareyama H, Satoh C and Fujimoto S: Decreased E-cadherin expression in endometrial carcinoma is associated with tumor dedifferentiation and deep myometrial invasion. Gynecol Oncol 53: 183-189, 1994.

8. Yang J, Mani SA, Donaher JL, Ramaswamy S, Itzykson RA, Come C, Savagner P, Gitelman I, Richardson A and Weinberg RA Twist, a master regulator of morphogenesis, plays an essential role in tumor metastasis. Cell 117: 927-939, 2004.

9. Vernon AE and LaBonne C: Tumor metastasis: A new Twist on epithelial-mesenchymal transitions. Curr Biol 14: R719-R721, 2004.

10. Puisieux A, Valsesia-Wittmann S and Ansieau S: A twist for survival and cancer progression. Br J Cancer 94: 13-17, 2006.

11. Deng JJ, Zhang W, Xu XM, Zhang F, Tao WP, Ye JJ and Ge W: Twist mediates an aggressive phenotype in human colorectal cancer cells. Int J Oncol 48: 1117-1124, 2016.

12. Yang J, Hou Y, Zhou M, Wen S, Zhou J, Xu L, Tang X, Du YE, $\mathrm{Hu} \mathrm{P}$ and Liu M: Twist induces epithelial-mesenchymal transition and cell motility in breast cancer via ITGB1-FAK/ILK signaling axis and its associated downstream network. Int J Biochem Cell Biol 71: 62-71, 2016
13. Fan Q, Qiu MT, Zhu Z, Zhou JH, Chen L, Zhou Y, Gu W, Wang LH, $\mathrm{Li} \mathrm{ZN}, \mathrm{Xu} Y$, et al: Twist induces epithelial-mesenchymal transition in cervical carcinogenesis by regulating the TGF- $\beta / \mathrm{Smad} 3$ signaling pathway. Oncol Rep 34: 1787-1794, 2015.

14. Kwok WK, Ling MT, Lee TW, Lau TC, Zhou C, Zhang X, Chua CW, Chan KW, Chan FL, Glackin C, et al: Up-regulation of Twist in prostate cancer and its implication as a therapeutic target. Cancer Res 65: 5153-5162, 2005.

15. Lee TK, Poon RT, Yuen AP, Ling MT, Kwok WK, Wang XH, Wong YC, Guan XY, Man K, Chau KL, et al: Twist overexpression correlates with hepatocellular carcinoma metastasis through induction of epithelial-mesenchymal transition. Clin Cancer Res 12: 5369-5376, 2006.

16. Tang H, Massi D, Hemmings BA, Mandalà M, Hu Z, Wicki A and Xue G: AKT-ions with a TWIST between EMT and MET. Oncotarget 7: 62767-62777, 2016.

17. Lai YJ, Lin CI, Wang CL and Chao JI: Expression of survivin and p53 modulates honokiol-induced apoptosis in colorectal cancer cells. J Cell Biochem 115: 1888-1899, 2014.

18. Lee SM, Kwon JI, Choi YH, Eom HS, and Chi GY: Induction of G2/M arrest and apoptosis by water extract of Strychni Semen in human gastric carcinoma AGS cells. Phytother Res 22: 752-758, 2008.

19. Yunlan L, Juan Z and Qingshan L: Antitumor activity of Di-n-Butyl(2,6-difluorobenzo-hydroxamato) tin (IV) against human gastric carcinoma SGC-7901 cells via G2/M cell cycle arrest and cell apoptosis. PLoS One 9: e90793, 2014.

20. Maestro R, Dei Tos AP, Hamamori Y, Krasnokutsky S, Sartorelli V, Kedes L, Doglioni C, Beach DH and Hannon GJ: Twist is a potential oncogene that inhibits apoptosis. Genes 13: 2207-2217, 1999

21. Van Doorn R, Dijkman R, Vermeer MH, Out-Luiting JJ, vander Raaij-Helmer EM, Willemze R and Tensen CP: Aberrant expression of the tyrosine kinase receptor EphA4 and the transcription factor twist in Sézary syndrome identified by gene expression analysis. Cancer Res 64: 5578-5586, 2004.

22. Vichalkovski A, Gresko E, Hess D, Restuccia DF and Hemmings BA: PKB/AKTphosphorylation of the transcription factor Twist-1 at Ser42 inhibits p53 activity in response to DNA damage. Oncogene 29: 3554-3565, 2010.

23. Horikawa T, Yang J, Kondo S, Yoshizaki T, Joab I, Furukawa M and Pagano JS: Twist and epithelial-mesenchymal transition are induced by the EBV oncoprotein latent membrane protein 1 and are associated with metastatic nasopharyngeal carcinoma. Cancer Res 67: 1970-1978, 2007.

24. Cheng GZ, Chan J, Wang Q, Zhang W, Sun CD and Wang LH: Twist transcriptionally up-regulates AKT2 in breast cancer cells leading to increased migration, invasion, and resistance to paclitaxel. Cancer Res 67: 1979-1987, 2007. 